\section{Reply to Waldorf}

\author{
J. PATRICK GRAY \\ University of Wisconsin \\ LINDA D. WOLFE \\ University of Florida
}

Waldorf's comments indicate a misunderstanding of both the intent and content of our paper. Three confusions are serious enough to demand clarification.

First, we did not "downgrade" the scientific status of sociobiology nor did we admit creationism into the domain of science. Most researchers of the evolutionary biology of social behavior accept the social, methodological, and philosophical rules that constitute scientific discourse. These rules are brought to bear on the type of speculations discussed in our paper. We were concerned with the use of some aspects of sociobiological theory in a field of discourse located outside of science. A study of the use of sociobiological concepts in popular discourse is not a rejection of the discipline's scientific status. We believe the scientific community's judgment on the validity of sociobiology will be made on scientific grounds, independent of the success of sociobiology in popular discourse. We note, on the other hand, that the rejection of an idea by the scientific community does not automatically extinguish the idea from popular discourse. This is demonstrated by the resilience of the essentialistic concept of race in the Western world.

The case of creationism is simpler: creationists do not accept most of the social, methodological, and philosophical rules of scientific discourse and therefore their work is not to be categorized as science.

Second, popular sociobiology and creationism are only two of a multitude of ethnosociologies available to Americans. Many uphold the moral values discussed in our paper while others offer different values. We sug. gested that to become a cultural fashion any ethnosociology must address the cognitive problems inherent in the American secular world view. We further argued this constraint structures ethnosociologies so that they take one out of a limited number of shapes, regardless of their source material (religion, art, science, etc.). Waldorfs discussion of the anti-technology movement is not relevant to our paper, since we did not claim that creationists and popular sociobiologists reject the belief in the "goodness of science." Most accept this belief but still seek a foundation for it. An investigation of the anti-technology movement along the cognitive lines we suggested and the Durkheimian lines Douglas and Wildavsky (1982) use to explore environmental movements would be rewarding.

Finally, Waldorf's misunderstanding is especially apparent in the statement that viewing popular sociobiology and creationism as ethnosociologies removes them from the arena of "serious discourse." Quite the opposite. We do not know Waldorf's criteria for serious discourse, but we believe discourses that suggest a foundation for morality, describe human nature, and define the meaning of existence qualify as serious. Ignoring popular discourses because they are not scientific or because we do not agree with them is anthropologically in. excusable and politically naive.

\section{REFERENCES CITED} Douglas, Mary, and Aaron Wildavsky
1982 Risk and Culture. Berkeley: Univer-
sity of California Press.

\section{A Note on Nuer Segmentary Organization}

\author{
RAYMOND C. KELLY \\ University of Michigan
}

In a recent article $(A A 84: 566-579,1982)$, Verdon maintains that Nuer segmentary organization is simply "a pattern of military alliances" that is "translated into the language of agnatic kinship," but is not, in fact, based on agnatic relations or, indeed, genealogical relations (pp. 574-575). Verdon asserts, following Glickman (1972), that patterns of association and alliance between Nuer wet season settlements are reducible to "ecological exigencies" (p. 574). In brief, a tribe (which constitutes the largest group regularly allied for military purposes) is simply coterminous with a dry season herding group. Verdon supports this assertion by citing Lienhardt's (1958) analysis of the Dinka (in which a tribe is said to be defined in relation to shared dry season pastures) and by proposing that "there is no reason to expect the Nuer to act differently" (p. 577). 
This is a startling statement for an anthropol. ogist to make and one I cannot allow to go unchallenged. There are, indeed, quite good reasons to expect differences between the Nuer and Dinka in this and other respects. Among the more prominent of these reasons is that Lienhardt's (1958) analysis is expressly directed to specifying differences between the Nuer and Dinka in segmentary organization. Such comparative analysis was one of the principal objectives of the volume in which Lienhardt's paper is published.

It is ironic that Verdon criticizes the widespread application of Evans-Pritchard's model of the Nuer segmentary lineage system in the analysis of other societies, inasmuch as he uncritically imposes Lienhardt's model of Dinka social organization on the Nuer case only a few pages later.

Verdon's claim that Nuer patterns of association are reducible to ecological exigencies can be assessed in terms of data provided by Evans-Pritchard (1940). However, these data do not support Verdon's assertions (or Glickman's argument on which these assertions are based). Evans-Pritchard's (ibid:56, 58, 60) maps of the distribution of tribal sections in the dry season show quite clearly that there is no association between joint herding and tribal identity. The Lou Nuer, for example, repair to four widely separated locations in the dry season. Yet they not only constitute a tribe (in Evans-Pritchard's sense), but also conform to a "pattern of military alliance" among territorial groups (in Verdon's terminology). Moreover, several of these Lou dry season aggregations share pastures with neighboring Dinka groups. However, this does not engender a pattern of military alliance among the Nuer and Dinka aggregated at the same locations, but instead leads to quite the opposite: armed conflict (ibid.:62). This same lack of correspondence between dry season aggregations and patterns of alliance is the norm. For example, portions of the Kwacbur section of the Lak tribe share dry season pastures with the Riah section of the Thiang tribe (ibid.:60), yet the Kwacbur identify themselves as part of Lak and form military alliances accordingly. Whether the Lak unit represents a "pattern of military alliance" that is merely "translated into the language of agnatic kinship" is a separate issue that cannot be addressed in this brief note. However, it is quite clear that this pattern of alliance is not purely a product of joint herding, and this suggests that it has some other basis-perhaps even the agnatic idiom in which it is cast.

\section{REFERENCES CITED}

Evans-Pritchard, E. E.

1940 The Nuer. London: Oxford University Press.

Glickman, Maurice

1972 The Nuer and the Dinka: A Further

Note. Man 7:586-594.

Lienhardt, Godfrey

1958 The Western Dinka. In Tribes Without Rulers. John Middleton and David Tait, eds. pp. 97-135. London: Routledge and Kegan Paul.

Verdon, Michel

1982 Where Have All Their Lineages Gone? Cattle and Descent among the Nuer. American Anthropologist 84:566-579.

\section{Response to Kelly}

\section{MICHEL VERDON \\ University of Cambridge}

Contrary to Kelly's accusations I wrote ( $A A$ $84: 566-579,1982)$ that Nuer military coalitions were built on the basis of agnatic connections (p. 575). One might say that they are rooted in agnatic connections, but not reducible to them, since other connections are also found to underlie military alliances (Holy 1979) and since, above all, agnatic connections in themselves cannot answer two specific questions: (1) Why does their recollection stop at a given level, delineating a maximal network of alliances (the Nuer "tribe")? (2) Why, within the "tribe," have ethnographers identified sublevels of groupings (the so-called "sections")? Although intrinsically important in themselves, these questions were peripheral to the main thrust of my article and could have been omitted without altering its content. I nonetheless dedicated three lines of the main text and one footnote to them, and this is where Kelly focuses his criticism.

Agnatic connections cannot answer these two questions-unless one wishes to invoke an Aristotelian "principle of segmentation" or to indulge in cultural transcendentalism-and they must therefore be related to something outside themselves. Peters had already written that the pattern of segmentary alliances among the Bedouin corresponded to ecological micro- 